\title{
Rough estimation of cell numbers in 5G networks using simple mathematical calculations
}

\author{
Sara Klisara ${ }^{1}$, Nermin Goran ${ }^{2}$, Elma Avdagić-Golub ${ }^{1}$ \\ ${ }^{1}$ University of Sarajevo, Faculty of Traffic and Communiactions, 71000 Sarajevo, Bosnia and Herzegovina \\ ${ }^{2}$ BH Telecom JSC, 71000 Sarajevo, Bosnia and Herzegovina
}

\begin{abstract}
This paper focuses on the problem of $5 \mathrm{G}$ network cell planning. In addition, it presents an example of a rough estimation of the required number of cells or base stations in a certain area for arbitrary number of users who are provided with a certain bandwidth per user within these cells. The cell number estimation is the initial step and the essence of planning and implementation of 5G network in an area. It is helpful for the operators to create and take into the account business plans in order to fully implement the network as a function of number of users which have to be served. Considering that, knowing the rough number of $5 \mathrm{G}$ base stations per user is very important for pre-sale activities and eventually necessity for widening of the initial investments. Therefore, the paper presents four scenarios that include different network parameters. Depending on the network parameters, the required number of base stations in a certain area changes. Given scenarios are examples of one $5 \mathrm{G}$ network in virtual area per bandwidth per user.
\end{abstract}

Keywords: cell planning, $5 G$ base station, throughput, radio link budget

\section{Introduction}

Radio Network Planning (RNP) plays a significant role in the development of cell design. Operators need to develop a wireless cellular network in the most profitable way possible, taking into account all parameters that may affect it, such as the environment, the (un)predictable number of users, the base station arrangements, path loss and the frequency scheme patterns. Effective radio access network planning needs to serve low cost of own infrastructure but also to satisfy users in planned area [1].

To solve challenges of $5 \mathrm{G}$ cell planning, multi-layer architecture consisting of macrocells and different types of small cells need to be considered as well as relays and D2D networks (device to device). It should be adopted in order to meet the requirements for spectral and energy efficiency and users with different throughput requirements and Quality of Services (QoS) [2]. Radio Access Technology of $5 \mathrm{G}$ networks do not necessarily have to be compatible with previous generations. However, similar to earlier cellular generations, technology developments should be compatible with its initial settings [3]. Therefore, $5 \mathrm{G}$ does not mean shutting down $3 \mathrm{G}$ and $4 \mathrm{G}$ systems but integrating them as components of macrocells and at the same time developing $5 \mathrm{G}$ access part via micro, pico, and femtocells that will operate on $\mathrm{GHz}$ bands, up to $60 \mathrm{GHz}$, channel widths up to $1 \mathrm{GHz}$, and access rates theoretically up to 10 Gbps in ideal conditions [2]. These short-range cells practically look like public Wi-Fi nodes. Therefore, the basic feature of $5 \mathrm{G}$ systems is heterogeneous networks composed of several small densities of distributed base stations to increase capacity and coverage. The millimeter-wave range uses cells of limited radius $(<100$ $\mathrm{m})$ to reduce path propagation attenuation in order to provide a huge throughput.

Small lengths of radio waves require very small antennas or antenna systems which means that $5 \mathrm{G}$ uses a large number of them. Control of the phase and amplitude of the signal, using a series of antennas and beamforming, helps to increase efficiency of electromagnetic waves in the desired direction, and cancel it in all other directions. This requires the knowledge of a direction of electromagnetic beams in air interface [4]. 5G NR (New Radio) is a global wireless standard for the new $5 \mathrm{G}$ air interface that evolved in $3 \mathrm{GPP}$ release 15 . In addition, $5 \mathrm{G}$ NR has the ability to connect to the Internet of Things (IoT/IoE) [3]. Today, mobile networks change the paradigm that the base station (BS) is the center of the network and move it to a device which now becomes the center of the mobile network [5]. 
Thus, the researchers focus on the design of a usercentric network. The user is no longer the last point in wireless network but is expected to participate in storage, content delivery exchange and budgeting within the network. This new paradigm implies a change in network architecture in which network management is coordinated and automated from a central cloud system, but at the same time, traffic management is distributed so that the shortest path passes between end devices, with the least delay. The network is logically organized into segments in which traffic is treated according to the nature of the application which is transmitted [6].

\section{5G radio network planning}

Concept of radio channel modelling is one of the most important tasks in the cellular network planning. There are different models that have been developed and are being researched. Due to differences in geographical topologies at the global level, and even within one country, instead of one uniform model, different models should be used. As an example of a strategy is one of the models which could be based on highly accurate 3D environmental data maps with ray-tracing (RT) principles in the densest urban areas, while at the same time it avoids estimation of coverage accuracy in the rural and suburban area [7].

The basis of radio link budget is the same as in previous mobile systems, the path loss is estimated based on key parameters, taking into account the set of gains and losses. The basis for estimating the coverage area is, therefore, the capacity offered in terms of data transfer rate and the corresponding achievable coverage area. If the data transfer rate is higher, then the coverage is lower [6]. This means that the highest bit rates are achieved near the base station, while the lowest rates are available in the edge of the coverage area of the cell. The aim of the initial planning phase of the $5 \mathrm{G}$ radio network is to obtain a rough estimate of coverage and capacity within the planning area, which is the aim of this paper. The first assumption is that the users in the cells are uniformly distributed and the second $5 \mathrm{G}$ can manipulate with power (NOMA). This estimation used a radio link budget. Radio link budget serves as a simple tool to estimate the achieved values of path losses over the planned environment, between the transmitter and receiver in the uplink (UL) and downlink (DL) directions. One of the advantages of this nominal planning phase is achieving a high-level estimation of the number of base stations needed to service the planned area considering user bit rate needs.

\subsection{Throughput calculation}

Throughput of the $5 \mathrm{G}$ network is significantly larger than $4 \mathrm{G}$, delivering up to maximum $20 \mathrm{Gbps}$ data rates and an average transfer rate of $100+$ Mbps. The approximate data transfer rate in $5 \mathrm{G} \mathrm{NR}$ can be calculated according to Eq. (1) [8].

$$
\begin{aligned}
& \text { data rate }(\text { Mbps })=10^{-6} * \sum_{j=1}^{J}\left(v_{\text {Layers }}^{(j)} * Q_{m}^{(j)} *\right. \\
& \left.f^{(j)} * R_{\max } * \frac{N_{P R B}^{B W(j), \mu_{* 12}}}{T_{s}^{\mu}} *\left(1-O H^{(j)}\right)\right)
\end{aligned}
$$

The used elements in the above equation are:

- $\quad 10^{-6}$ - constant (because of Mbps),

- $\quad \sum$ - sum of subcarrier,

- $\quad v_{\text {Layers }}^{(j)}-$ number of layers, i.e., transmitters,

- $Q_{m}^{(j)}$ - type of modulation. (2-QPSK, 4-16 QAM, 6-64 QAM, 8-256 QAM, ...)

- $f^{(j)}$ - scaling factor (varies from $0.4,0.75,0.8,1$ ),

- $R_{\max }$ - the value depends on the encoding type of 3GPP 38.212 and 3GPP 38.214. (For LDPC code the maximum number is $948 / 1024=0,92578125$ ),

- $B W_{(j)}$ - bandwidth (MHz), should be selected with frequency band and $\mu(i)$ configuration,

- $\quad N_{P R B}^{B W(j), \mu}$ - the maximum number of PRBs for the selected $B W_{(j)}, F R_{(j)}, \mu_{(j)}$,

- $O H^{(j)}$ - header for control channels,

- $T_{s}^{\mu}$ - the average duration of the OFDM symbol in the subframe for the value $\mu_{(\mathrm{i})}$ for the normal cyclic prefix, which is calculated according from Eq. (2):

$T_{s}^{\mu}=\frac{10^{-3}}{14 * 2^{\mu}}$

In (1) the parameter $J$ means the size of the subcarriers.

The calculation of throughput is based on the 3GPP TS 38.306 standard. Radio Access Capabilities NR User Equipment (UE) uses the formula to obtain the $5 \mathrm{G} \mathrm{NR}$ data rate in DL (downlink) and UL (uplink). In order to obtain an accurate result, it is necessary to enter the important network parameters $(5 \mathrm{G}$ network mode, number of aggregate carriers, number of MIMO layers, frequency band, type of modulation, etc.), which will be described in Chapter 3 for a few scenarios.

\subsection{G NR Link budget}

The radio link budget is the calculation of the total gain and loss in the system in order to get Received Signal Level (RSL) [9]. The level of the received signal is compared with the sensitivity of the receiver to check whether the channel status is appropriate or not. The channel status is marked as "Pass" if the level of the received signal is better than the reception sensitivity of receiver, otherwise it is marked as "Fail" [10]. The link budget in these circumstances is depicted on Figure 1. 


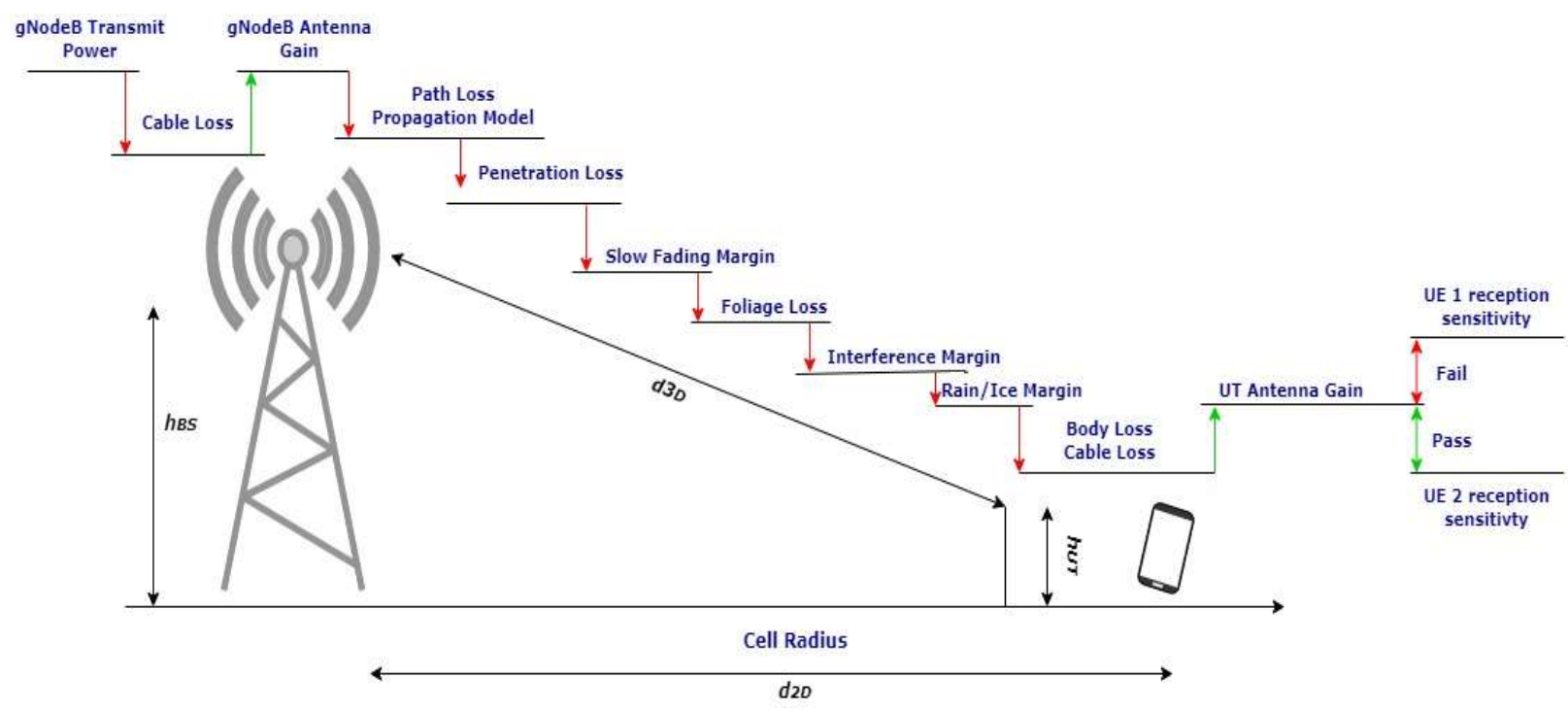

Figure 2. 5G Link budget

The link budget of the 5G NR connection, according to the 3GPP 38.901 standard, is calculated according to Eq. (3) [11]:

\section{Radio link $k_{\text {Received Signal Level at receiver }(\mathrm{dBm})}=$}

gNodeB transmit power ${ }_{T X}$ bandwidth +

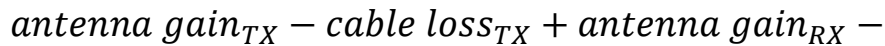
cable loss $_{R X}-$ path loss propagation model $^{-}$ penetration loss $s_{d B}-$ foliage loss $_{d B}-$ body block loss $_{d B}$ - interference margin mb $_{d B}-$ rain or ice margin $_{d B}-$ slow fading margin $_{d B}-$ penetration loss $_{\text {indoor }}-$ Attenuation $_{\text {indoor }}$

where transmit power represents Node B power or UE TX power which is used for current data transmission.

Path loss is the weakening of the power of the electromagnetic wave as it propagates through space. Path loss is also affected by the contours of the terrain, the environment (urban or rural, vegetation and leaves), the propagation medium (dry or moist air), the distance between the transmitter and receiver, and the height and location of the antennas [12]. The $5 \mathrm{G}$ propagation models defined in 3GPP 36,873 are used to calculate path loss. 5G uses 3D UMa propagation models, UMi and RMa models, which are applicable in the $2-6 \mathrm{GHz}$ frequency bands and then extended to $0.5-100 \mathrm{GHz}$ in $3 \mathrm{GPP} 38.90$.

If the cell radius corresponds to the maximum range of the cells, then the path loss will correspond to the Maximum Allowable Path Loss (MAPL) [10]. When the path loss value is calculated, then it is possible to calculate the level of the received signal that will be compared to the sensitivity of the receiver.

After calculating the path loss, if we know the center frequency, the radius of the cell can be deduced. Path Loss is calculated according to Eq. (4) [13]:
Path Loss $(P L)=28.0+22 \log 10(d)+$ $20 \log 10(f c)$

The cell radius is calculated by the Eq. (5) [10]:

$$
\text { Distance }(d)=10 \text { Power }\left(\frac{P L-28-20 * \log 10(f c)}{22}\right)
$$

The link budget allows us to calculate the cell radius according to the receiver sensitivity or the received signal level for a given cell radius and compare them with the reception sensitivity to check the channel status (successful or unsuccessful). Reception sensitivity is mainly based on capacity requirements (bandwidth) because the SINR (Signal to Interference and Noise Ratio) value is directly related to the bandwidth we want to achieve at the cell edge [14].

After calculating the throughput of one cell, which contains a certain number of users, the throughput for one user in that cell is calculated, according to Eq. (6):

Throughput for one user $=\frac{\text { Throughput }}{\text { number of user }} * C$

The $C$ is constant which depends on arbitrary number of active users. By calculating the radius of the cell, the required number of base stations in one area is determined. The coverage of the square area of one base station is calculated according to Eq. (7):

$$
\text { Coverage Area }=R^{2} \pi
$$

It is obvious, the assumption is that cells are circle shaped. Determining the coverage area of one base station 
is a prerequisite for determining the required number of $5 \mathrm{G}$ base stations, which is calculated according to Eq. (8):

$$
5 G \operatorname{gNode} B=\frac{S_{q}}{C_{a}}
$$

Where is:

$S_{q}$ - total surface area of the cluster in square area

$C_{a}-$ coverage area of single gNB

In the next chapter, the network parameters necessary for the specified budget will be calculated.

\section{Networks Parameters for link budget}

Before calculating the number of cells using mathematical relations, it is necessary to set certain network parameters. The simulation is performed on an arbitrary number of users, in this case, 100 users in one cell with a ratio of $1: 10$.

The reason for this ratio is that not all users in the cell use the maximum data rate assigned to them at the same time. In the (6) it is marked with $C$. When we consider cell size, the first step is to take an arbitrary size of one cell. The size of a cell with a radius of $214 \mathrm{~m}$ is taken for these scenarios. Additional parameters required for the budget are:

$$
\begin{array}{ll}
- & v_{\text {Layers }}^{(j)}=4 \\
- & Q_{m}^{(j)}=8-256 \text { QAM } \\
- & f^{(j)}=1
\end{array}
$$

The size of the subcarriers (parameter $\mu$ ) is determined via the carrier configuration values in the intervals of 0 $15 \mathrm{kHz}, 1-30 \mathrm{kHz}$, and $2-60 \mathrm{kHz}$ (taken from $3 \mathrm{GPP}$ 38.211 ). Subcarriers' sizes of 30 and $60 \mathrm{kHz}$ were taken for this scenario. The number of resource blocks is taken from Table 1, as recommended in [15], where the number of resource blocks is taken for a certain bandwidth and certain number of subcarriers.

The header value for the control channels $\mathrm{OH}$ for the downlink is 0.14 in F1 band and 0.18 in F2 band, while for the uplink it is 0.08 in F1 band and 0.10 in F2 band. The frequency range $\mathrm{F} 1$ is from 450 to $6000 \mathrm{MHz}$ and the frequency range F2 is from 6000 to $52600 \mathrm{MHz}$.

TDD (Time Division Duplex) was chosen for the spectrum use technique, because TDD uses one frequency for uplink and downlink but they are transmitted at different times, which makes it more convenient in comparison with using paired spectrum (FDD Frequency Division Duplex), especially when it is not available [16]. That is, increasing the data rate per user is done by assigning multiple frequency blocks to the same user [17]. The values of individual parameters in each scenario are presented in Table 2.

Values of Radio link budget $(\mathrm{dBm})$, receiver sensitivity $(\mathrm{dBm})$, radio channel status, and path loss are required for link budget. The propagation model to be used in this case is Urban Macro 3D-UMa LOS + NLOS. As it can be seen in Figure 3., multiple parameters affect the attenuation of the signal during propagation. Table 3 shows the values of individual parameters affecting the connection calculation, which were used in the scenarios.

\begin{tabular}{|c|c|c|c|c|c|c|c|c|}
\hline Scenario & $\begin{array}{c}\text { Scenario } \\
1\end{array}$ & $\begin{array}{c}\text { Scenario } \\
1\end{array}$ & $\begin{array}{c}\text { Scenario } \\
2\end{array}$ & $\begin{array}{c}\text { Scenario } \\
2\end{array}$ & $\begin{array}{c}\text { Scenario } \\
3\end{array}$ & $\begin{array}{c}\text { Scenario } \\
3\end{array}$ & $\begin{array}{c}\text { Scenario } \\
4\end{array}$ & $\begin{array}{c}\text { Scenario } \\
4\end{array}$ \\
\hline Frequency band $(\mathrm{kHz})$ & $\begin{array}{c}\text { FR1 } \\
(\mu=30)\end{array}$ & $\begin{array}{c}\text { FR1 } \\
(\mu=30)\end{array}$ & $\begin{array}{c}\text { FR1 } \\
(\mu=30)\end{array}$ & $\begin{array}{c}\text { FR1 } \\
(\mu=30)\end{array}$ & $\begin{array}{c}\text { FR1 } \\
(\mu=30)\end{array}$ & $\begin{array}{c}\text { FR1 } \\
(\mu=30)\end{array}$ & $\begin{array}{c}\text { FR2 } \\
(\mu=30)\end{array}$ & $\begin{array}{c}\text { FR2 } \\
(\mu=30)\end{array}$ \\
\hline Bandwidth /MHz & 50 & 50 & 80 & 80 & 100 & 100 & 200 & 200 \\
\hline Scaling factor & 1 & 1 & 1 & 1 & 1 & 1 & 1 & 1 \\
\hline Modulation & $\begin{array}{c}8- \\
\text { 256QAM }\end{array}$ & $\begin{array}{c}8- \\
\text { 256QAM }\end{array}$ & $\begin{array}{c}\text { 8- } \\
\text { 256QAM }\end{array}$ & $\begin{array}{c}8- \\
\text { 256QAM }\end{array}$ & $\begin{array}{c}8- \\
\text { 256QAM }\end{array}$ & $\begin{array}{c}8- \\
\text { 256QAM }\end{array}$ & $\begin{array}{c}8- \\
\text { 256QAM }\end{array}$ & $\begin{array}{c}\text { 8- } \\
\text { 256QAM }\end{array}$ \\
\hline Number of transmitters & 4 & 4 & 4 & 4 & 4 & 4 & 4 & 4 \\
\hline $\begin{array}{l}\text { Direction of data transfer } \\
\text { DL/UL }\end{array}$ & DL & UL & DL & UL & DL & UL & DL & UL \\
\hline Duplex mod & TDD & TDD & TDD & TDD & TDD & TDD & TDD & TDD \\
\hline
\end{tabular}

Table 1: Maximum transmission bandwidth configuration NRB according to TS 3GPP TS 38.101

\begin{tabular}{|c|c|c|c|c|c|c|c|c|c|c|c|c|c|c|c|c|c|c|c|c|c|c|}
\hline $\begin{array}{c}\mathrm{SCS} \\
(\mathrm{kHz})\end{array}$ & $5 \mathrm{MHz}$ & $10 \mathrm{MHz}$ & $15 \mathrm{MHz}$ & $20 \mathrm{MHz}$ & $25 \mathrm{MHz}$ & $30 \mathrm{MHz}$ & $40 \mathrm{MHz}$ & $50 \mathrm{MHz}$ & $60 \mathrm{MHz}$ & $80 \mathrm{MHz}$ & $90 \mathrm{MHz}$ & $100 \mathrm{MHz}$ \\
\hline 15 & 25 & 52 & 79 & 106 & 133 & 160 & 216 & 270 & N/A & N/A & N/A & N/A \\
\hline 30 & 11 & 24 & 38 & 51 & 65 & 78 & 106 & 133 & 162 & 217 & 245 & 273 \\
\hline 60 & N/A & 11 & 18 & 24 & 31 & 38 & 51 & 65 & 79 & 107 & 121 & 136 \\
\hline
\end{tabular}

Table 4: Network parameters for different scenarios 
Table 5: Parameters for Link budget

\begin{tabular}{|l|c|c|}
\hline Frequency Band (Ghz): & 3.5 & 28 \\
\hline Body loss & 3 & 15 \\
\hline Dense tree & 8.5 & 15 \\
\hline Rain/Ice Margin & 0 & 3 \\
\hline Typical interference margin in DL & 6 & 1 \\
\hline Typical interference margin in & 2 & 0.5 \\
\hline O2O (Outdoor-to-Outdoor) & \multicolumn{2}{|c|}{ Urban } \\
Slow fading margin (dB) & 7 \\
\hline
\end{tabular}

The chosen type of coverage is Outdoor and we arbitrarily assume that the area is of a two-dimensional type of $4 \mathrm{~km}^{2}$.

\section{Results of base station number estimation}

Based on the input parameters used from Chapter 3, the throughput per user was calculated for four different scenarios. Each scenario individually calculates the throughput in one cell and the bandwidth or data rate for one user in that cell. For the first scenario, in the case of downlink and bandwidth of $50 \mathrm{MHz}$, we got the maximum throughput in one cell of $976 \mathrm{Mbps}$. For the second scenario, the throughput was $1592 \mathrm{Mbps}$, while for Scenario 3 with a bandwidth of $100 \mathrm{MHz}$, it was 2004 Mbps. In Scenario 4, the highest bandwidth was 200 $\mathrm{MHz}$, so the highest throughput was $3694 \mathrm{Mbps}$.

Throughput for one user in DL Scenario 1 is 97.6 Mbps, while in UL it is $26 \mathrm{Mbps}$. Scenario 4 gives the best results, where in DL for a value of total throughput of $3694 \mathrm{Mbps}$, for one user data transfer rate is $369.4 \mathrm{Mbps}$. In UL for $1014 \mathrm{Mbps}$, total throughput and the throughput for a single user is $101.4 \mathrm{Mbps}$. Comparative results of all scenarios for DL/UL can be shown in the Figure 2 and Figure 3.

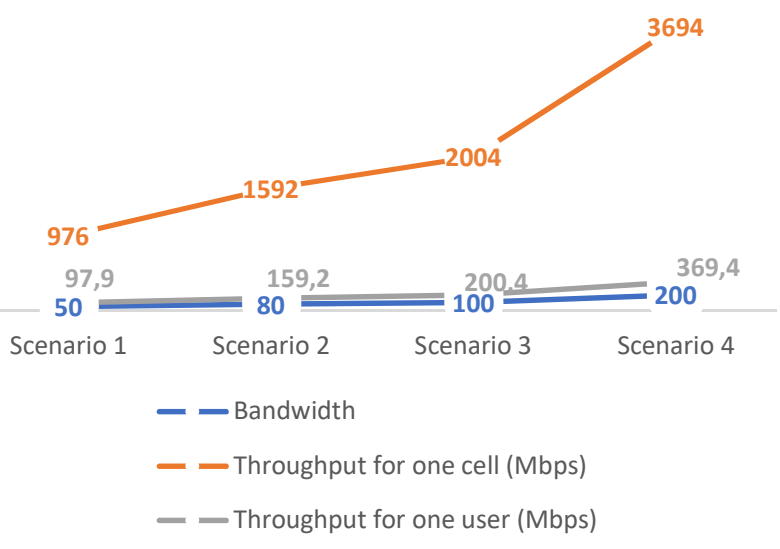

Figure 2. Throughput for multiple scenarios in DL

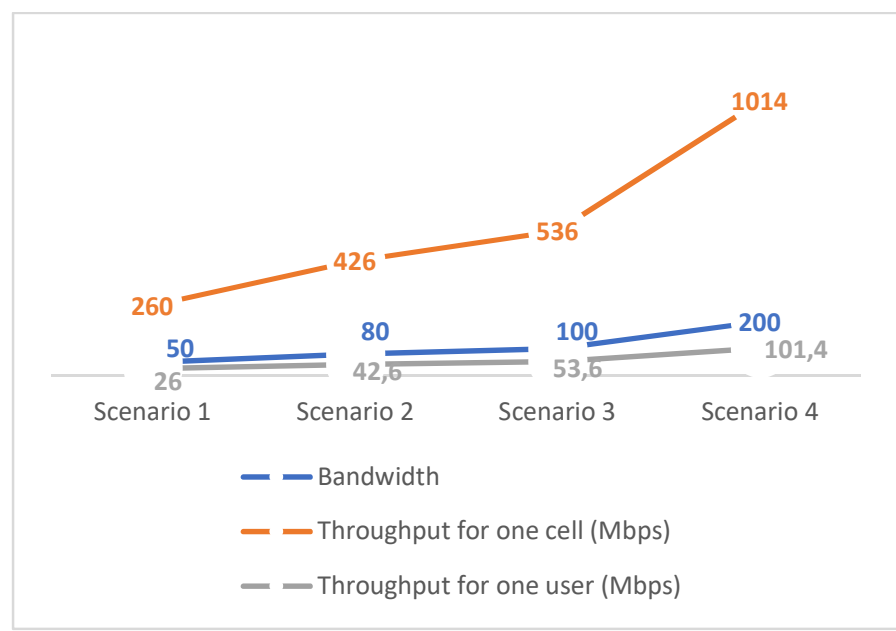

Figure 3. Throughput for multiple scenarios in UL

Table 6: Link budget

\begin{tabular}{|l|c|c|c|c|c|c|c|c|}
\hline Scenario & $\begin{array}{c}\text { Scenario } \\
\mathbf{1}\end{array}$ & $\begin{array}{c}\text { Scenario } \\
\mathbf{1}\end{array}$ & $\begin{array}{c}\text { Scenario } \\
\mathbf{2}\end{array}$ & $\begin{array}{c}\text { Scenario } \\
\mathbf{2}\end{array}$ & $\begin{array}{c}\text { Scenario } \\
\mathbf{3}\end{array}$ & $\begin{array}{c}\text { Scenario } \\
\mathbf{3}\end{array}$ & $\begin{array}{c}\text { Scenario } \\
\mathbf{4}\end{array}$ & $\begin{array}{c}\text { Scenario } \\
\mathbf{4}\end{array}$ \\
\hline Cell Radius $(\mathrm{m})$ & 214 & 214 & 214 & 214 & 214 & 214 & 214 & 214 \\
\hline $\begin{array}{l}\text { Center frequency } \\
(\mathrm{MHz})\end{array}$ & 2110 & 1920 & 2690 & 2570 & 26500 & 26500 & 29499 & 29499 \\
\hline Path loss (dB) & 135.8 & 131.8 & 137.91 & 133.52 & 174.16 & 173.66 & 175.21 & 174.71 \\
\hline $\begin{array}{l}\text { Receiver sensitivity } \\
(\mathrm{dBm})\end{array}$ & -116.44 & -117.44 & -116.44 & -117.44 & -111.43 & -113.43 & -114.43 & -114.43 \\
\hline $\begin{array}{l}\text { Received Signal } \\
\text { Level (dBm) }\end{array}$ & -63.3 & -89.3 & -65.41 & -91.02 & -122.66 & -131.16 & -102.71 & -132.21 \\
\hline Link status & Pass & Pass & Pass & Pass & Fail & Fail & Pass & Fail \\
\hline
\end{tabular}


Table 7 presents the results of the radio link budget, where we can notice that for different values of the center frequency and the same values of the radius of the cell, different final results of the path loss, the sensitivity of the receiver as well as the signal level on the receiver were obtained.

If the radius of the cell decreased or increased for these same values, the status of the radio channel would change. Figure 4 and Figure 5 show a comparative calculation of the radio link for DL and UL, respectively.

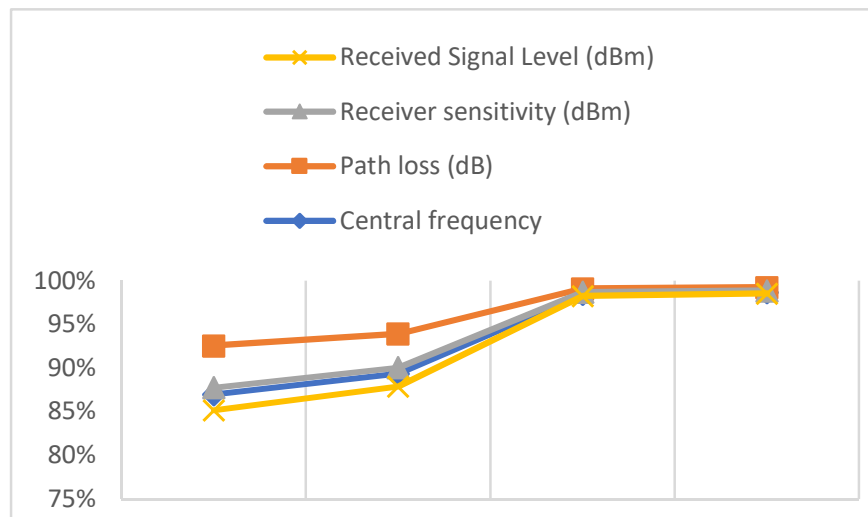

SCENARIO 1 SCENARIO 2 SCENARIO 3 SCENARIO 4

Figure 4. Radio Link Budget in DL

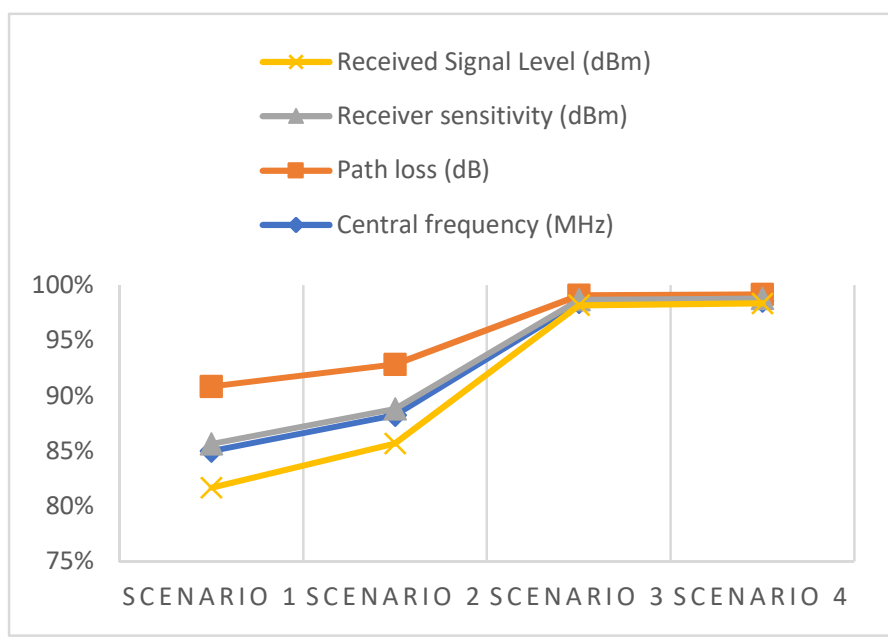

Figure 5. Radio Link Budget in UL

The coverage of the square area of one base station is $143872.377 \mathrm{~m}^{2} \approx 0.14387 \mathrm{~km}^{2}$. We conclude that a square area of $4 \mathrm{~km}^{2}$ (representing one cluster) requires 28 base stations with a radius of $214 \mathrm{~m}$ (Figure 6), in order to fully cover this area with a $5 \mathrm{G}$ signal and to provide each user with the required data speed.

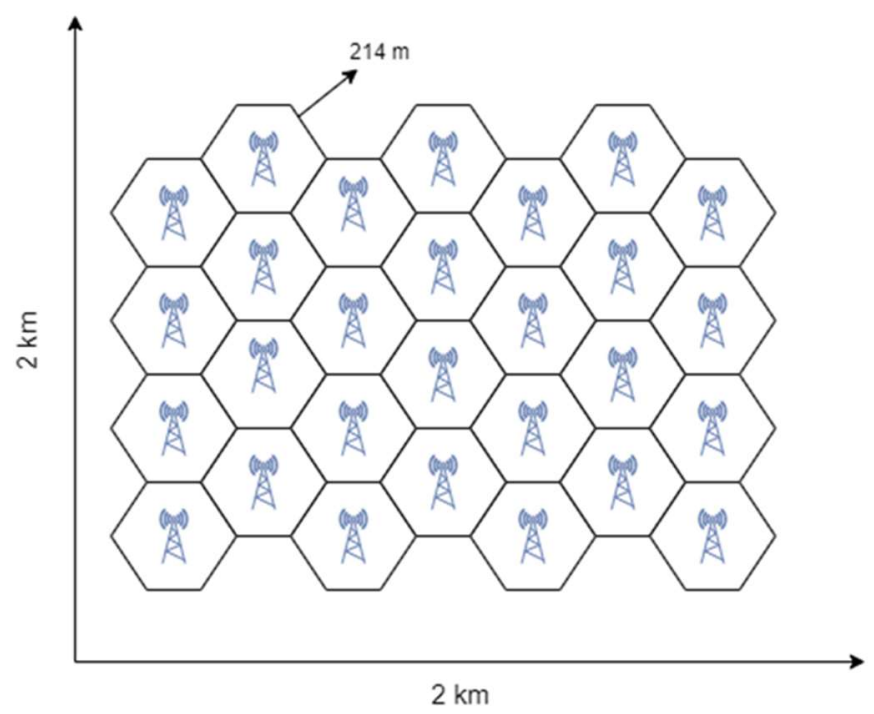

Figure 6. Cluster

\section{Conclusion}

The paper presents a simple mathematical model for cell planning which can be used in rough estimation of cell numbers. Further, the obtained data can be helpful in initial investment plans where the knowledge of cell number is crucial for final business impact. Proper and detailed planning of the radio network is an important stage in the planning of the entire network because the radio network can have a great impact on implementation costs, optimization of base station locations, used power, antenna heights, and other practical aspects. Return on investment can vary significantly.

In the future works we plan to research different models which include different path loss calculation in urban, suburban or rural area. In addition, it should be tried to adjust presented calculation of cell number in different geographical terrain configurations.

\section{References}

[1] H. M. Tun, "Radio Network Planning and Optimization for 5G Telecommunication System," Computer Science Research, 2021.

[2] R. K. J. A. Gupta, "Survey of 5G Network: Architecture and Emerging Technologies," IEEE Access, vol. 3, p. 1206 - 1232, 2015.

[3] A. R. Mishra, Introduction to 5G Network Planning and Optimization, John Wiley \& Sons Ltd., 2018, pp. 295-313.

[4] G. J. a. L. T. Korakis, "A MAC protocol for fullexploitation of directional antennas in ad-hoc wireless networks," Proc. ACM Int. Symp. Mobile Ad Hoc Netw. Comput., p. 97-108, 2003. 
[5] J. al., "What will 5G be," IEEE J. Sel. Areas Commun, vol. 32, no. 6, p. 1065-1082, 2014.

[6] S. C. a. J. Zhao, "The requirements, challenges, and technologies for $5 \mathrm{G}$ of terrestrial mobile telecommunication," IEEE Commun. Mag, vol. 52, no. 5, p. 36-43, 2014.

[7] J. T. Penttinen, 5G Network Planning and Optimization, Wiley Telecom, 2019.

[8] V. Oleg, "5G-tools," 2021. [Online]. Available: https://5g-tools.com. [Accessed 1810 2021].

[9] K. Bechta, J. Du and M. Rybakowski, "Rework the Radio Link Budget for $5 \mathrm{G}$ and Beyond," IEEE Access 8:211585-211594, 2020.

[10] Techplayon, "5G Network RF Planning - Link Budget Basics," 2019, no. https://www.techplayon.com/5gnetwork-rf-planning-link-budget-basics/.

[11] 3GPP, "Study on channel model for frequencies from 0.5 to $100 \mathrm{GHz}$ Release 14," Specification \#: 38.901, 2017.

[12] A. O. Akanni and A. N. Oliseloke, "Validation of Egli Model and Estimation of Pathloss," International Journal of Research and Innovation in Applied Science (IJRIAS), vol. V, no. IX, 2020.

[13] S. Sousa, F. J. Velez and J. M. Peha, "Impact of Propagation Model on Capacity in Small-cell Networks," in 2017 International Symposium on Performance Evaluation of Computer and Telecommunication Systems (SPECTS), 2017.

[14] Techplayon, "5G Network RF Planning - Link Budget Basics," 2019. [Online]. Available: https:/www.techplayon.com/5g-network-rf-planninglink-budget-basics/.

[15] 3GPP, "5G;NR; User Equipment (UE) radio transmission and reception; Part 4: Performance requirements," TS 38.101- 4 version 15.2.0 Release 15.

[16] H.Wymeersch and A.Eryilmaz, "Chapter 12 - Multiple access control in wireless networks," in Academic Press Library in Mobile and Wireless Communications, Elsevier Ltd, 2016, pp. 435-465.

[17] C. Sbeglia, "Understanding FDD/TDD carrier aggregation for 5G," 2021. [Online]. Available: https://www.rcrwireless.com/20210420/5g/understan ding-fdd-tdd-carrier-aggregation-for-5g. 